\title{
EFICÁCIA DA SENTENÇA E COISA JULGADA PERANTE TERCEIROS
}

\author{
Negi Calixto * \\ Victor A. A. Bonfim Marins **
}

* Prof. Adjunto da Fac. de Direito do Setor de Ciências Jurídicas da UFPR. Desembargador do Tribunal de Justiça do Paraná.

* Prof. de Direito Processual Civil da Fac. de Direito de Curitiba e na Escola da Magistratura do Paraná.

SUMÁRIO: 1. Coisa Julgada. 2. Parte. 3. Terceiros. 4. Eficácia da sentença. 5. Eficácia da sentença e coisa julgada. 6. Eficácia da sentença $e$ coisa julgada perante terceiros. 7. Ações de Estado e Eficácia "erga omnes".

\section{COISA JULGADA}

Rotulada de "o mais grosseiro de todos os artefatos da ciência processual"; de "pesado embaraçante, como a armadura dos guerreiros medievais"1, a coisa julgada serve, entretanto, com grande eficiência à finalidade instrumental do processo, qual seja, a realização do direito objetivo conferindo indiscutibilidade à sentença e, por conseqüência, estabilidade às relações sociais. E se, na verdade, não compõe em sua inteireza o conflito de interesses, como realidade sociológica que $\mathrm{e}^{2}$, certamente contribui efetivamente para isso.

Vem de longa data a discussão acerca do conceito de coisa julgada, quiçá por ser o ponto culminante da atividade processual. Assinala CHIOVENDA que "o alvo do processo para os romanos é a atuação da vontade da lei, em relação a um determinado bem da vida (res in iudicium deducta)". E mais adiante: "A res iudicata outra coisa não é para os romanos do que a res in iudicium deducta depois que foi iudicata". E arremata, conceituando

\begin{tabular}{llllll}
\hline R. Fac. Direito & Curitiba & a. 25 & n. 25 & p. $93.108,1989$ & 93
\end{tabular}


a coisa julgada como "o bem julgado, o bem reconhecido ou desconhecido pelo juiz". 3

A Lei de Introdução ao Código Civil, em seu art. 69, § 3 ? estabelece: "Chama-se coisa julgada ou caso julgado a decisão judicial ae que já não caiba recurso". O Código de Processo Civil por sua vez, diz em seu art. 467: "Denomina-se coisa julgada material a eficácia, que torna imutável e indiscutivel a sentença não mais sujeita a recurso ordinário ou extraordinário".

A doutrina tradicional costumava ter a coisa julgada como "o efeito característico da sentença" ", ao lado certamente de outros efeitos que a sentença produz.

De fato, PEREIRA E SOUZA em suas "Primeiras Linhas Sobre - Processo Civil" já assinalava: "São effeitos da Sentença: 1. Produzir cousa julgada; 2. Fazer direito entre as Partes" (grafia original).$^{5}$

Essa doutrina, contudo, não proporcionou solução adequada aos demais efeitos da sentença, que permaneceriam distintos da coisa julgada, e portanto, não seriam atingidos por ela.

Outra corrente, mais moderna, predominante na literatura alemã, entende a coisa julgada como a eficácia inerente ao elemento declaratório da sentença. Entre nós, nessa linha de pensamento estão PONTES DE MIRANDA e CELSO NEVES. Diz o primeiro: "Quanảo somamos eficácia declarativa e força formal de coisa julgada (preclusão) é que podemos falar de eficácia de coisa julgada material". E o segundo: "Assentado que a coisa julgada reveste, apenas, o conteúdo declaratório da sentença, os demais elementos aparecem como conseqüência do que se decidiu, já no plano da realização prática de seus efeitos processuais, reservado à atividade executória do juiz".7

A maioria dos processualistas brasileiros, entretanto, segue o ensinamento de LIEBMAN, para quem a coisa julgada não é efeito da sentença, mas uma qualidade (a imutabilidade) dela e dos seus efeitos, vale dizer, modo de manifestarem-se desses efeitos. Na imutabilidade do comando da sentença estaria a autoridade da coisa julgada.

BARBOSA MOREIRA entende adjetiva a concepção de LIEBMAN e afirma que a fórmula alemã "padece de radical vício de impostação, o de deslocar para o campo ảos efeitos da sentença "a declaração que lhe integra (e em muitos casos the exaure) $o$ conteúdo". "A sentença" - continua o processualista - "não pro. duz uma declaraç̃o: contém-na". Sustenta também que são mutáveis os efeitos da sentença, tornando-se imutável, isto sim, com o trânsito em julgado o próprio conteúdo da decisão. ${ }^{9} \mathrm{O}$ trânsito 
em julgado vem a ser, assim, fato que marca o início de uma situação jurídica nova, caracterizada pela existência da coisa julgada - formal ou material, conforme o caso. Considera, destarte, como situação jurídica,10 a coisa julgada.

OVİIO A. BAPTISTA DA SILVA defende construção digamos conciliadora entre a doutrina clássica, que assimila coisa julgada à declaração contida na sentença e a doutrina de LIEBMAN, no sentido de reconhecer a coisa julgada não como qualidade que se agrega a todos os efeitos da sentença, mas tão somente ao seu efeito declaratório. Em suas palavras: "A coisa julgada ma. terial é a qualidade que se adiciona, em dadas circunstâncias, ao efeito declaratório da sentença, tornando-o indiscutivel". ${ }^{11}$ Explica, ainda, que todas as sentenças contêm eficácia declaratória, mas nem todas produzem coisa julgada material, como por exemplo, as proferidas nos procedimentos de jurisdição voluntária e as que julgam procedentes as ações cautelares.

A posição de OVÍDIO parece-nos a que mais atende aos reclamow finalísticos do processo, porque concilia virtudes de grandes correntes doutrinárias amenizando-lhes as inconveniências.

Antes de encerrarmos este tópico, não é demais lembrar, sem embargo de assente na doutrina, a distinção entre coisa julgada formal e material. Aquela se forma, como sabido, dentro do processo, em virtude de sentença não mais sujeita a recurso. Pressupõe portanto, a preclusão da fase recursal, a preclusão máxima, no dizer de CHIOVENDA. A coisa julgada formal impede reapreciação pelo órgão julgador da matéria decidida no mesmo processo. Uma vez verificada e tendo sido a lide também julgada, formase então a coisa julgada material, ou seja, ao conteúdo declaratório da sentença adiciona-se a imutabilidade. A indiscutibilidade resultante opera dentro e fora do processo. A coisa julgada material contém a coisa julgada formal. ${ }^{12}$

Para podermos estudar os reflexos da sentença nas relações jurídicas que têm terceiros como titulares, fazem-se necessárias algumas precisões sobre os conceitos de parte e terceiros.

\section{PARTE}

O conceito de parte é processual. A lide, como deduzida no processo, evidencia quem tem interesse em sua solução. A relação jurídica processual será formada, discutida e sentenciada em função da lide, da demanda, da controvérsia, tal qual descrita pelas partes. $\mathbf{E}$ bem verdade que, ao fundo, estará sempre presente a relação jurídica substancial, razão porque será natural pensar-se 
nas partes como possíveis sujeitos dessa relação jurídica. Vale obtemperar, entretantc, que a res in indicium deducta independe de relação material efetiva, porquanto não se exige àquela veracidade ou mesmo plausibilidade, matéria cuja averiguação é objeto do processo. "Ainda a esse propósito" - leciona CHIOVENDA "se reafirma a autonomia da ação e a independência da relaçáo processual quanto à relação substancial". ${ }^{13}$ Com efeito, poderá ocorrer que a relação substancial descrita nem sequer exista, ${ }^{14}$ ou seja falsa, ${ }^{15}$ ou não tenha como titular qualquer das partes do processo. ${ }^{16} \mathrm{E}$ ninguém afirmará que em qualquer desses casos o processo desenvolveu-se sem partes.

Dito isso podemos mencionar alguns conceitos: "Parte é aquele que demanda em seu próprio nome (ou em cujo nome é demandada a atuação duma vontade da lei, e aquele em face de quem essa atuação é demandada". ${ }^{17}$

PONTES DE MIRANDA escreve: "Partes são as pessoas para as quais e contra as quais é pedida a tutela jurídica". E logo adiante: "De regra, são as partes os sujeitos do direito e do dever (...). Todàvia, pode dar-se que terceiro, que não é o sujeito ativo ou passivo àa res deducta, possa ser parte, isto é, ter a "ação". De onde se tira que o conceito parte é de direito formal, e de ordinário coincide, porém não precisa coincidir, com o de titular do direito na relação jurídica controvertida, ou com o de sujeito passivo dessa relação". 18

Cabe consignar a legitimação ex-lege para serem partes, por exemplo, do síndico da falência, do inventariante, do administrador da massa concursal, do Ministério Público, os quais, no exercício dessas funções não detêm titularidade sobre a relação substancial controvertida.

Parece-nos, destarte, importante fixar c conceito de parte, assim para o processo complexivamente considerado, como em relação à coisa julgada material, cuja eficácia só às partes alcança.

Dos terceiros trataremos a seguir.

\section{TERCEIROS}

Definir singelamente terceiro como "aquele que não é parte" é incorrer em logomaquia, notadamente diante do C.P.C., cujo artigo $1.046 \S 2$ \% equipara a terceiro a própria parte "que, posto figure no processo, defende bens que, pelo título de sua aquisição ou pela qualidade em que os possuir, não podem ser atingidos pela apreensão judicial".

Além disso, há sopesar o vezo de alguns autores afirmarem 
suficiente a comparência do terceiro ao processo para ser considerado parte. Tais imprecisões contribuem para obscurecer os conceitos. Bem a propósito vem a lição de FREDERICO MARQUES: "Os embargos são de terceiro; mas como tal deve entenderse não a pessoa física ou jurídica que não tenha participado do feito, mas a pessoa titular de um direito outro que não tenha sido atingido pela decisão judicial". ${ }^{19}$ No mesmo sentido, PONTES DE MIRANDA: "Se a pessoa foi parte, mas a respeito de outra causa petendi, é terceiro, e não executado. Nem podia ser de outro modo". ${ }^{20}$

Como se observa, para, conceituar o terceiro deve-se pôr em mira não só a identidade das pessoas que atuam como sujeitos na causa, mas esta complexivamente considerada, nos seus elementos identificadores, advindo daí a identidade ou qualidade jurídica com que comparecem os sujeitos ao processo.

O art. 301, § 20 do Código de Processo Civil dispõe: "Uma ação é idêntica à outra quando tem as mesmas partes, a mesma causa de pedir e o mesmo pedido". São esses os elementos identificadores da causa. ${ }^{21}$ Por conseqüência, se direito ou interesse jurídico envolvido na causa, afigurar-se incompatível com o propósito dela ou com a eficácia da relação jurídica processual, o prejudicado, seja parte ou estranho, poderá defender-se utilizando a qualidade de terceiro. Nesse rumo vem a pêlo o conceito de OVfDIO BAPTISTA DA SILVA acerca da intervenção dos terceiros: Diz-se que há intervenção de terceiros no processo, quando alquém dele participa sem ser parte na causa, com o fim de auxiliar ou excluir os litigantes, para defender algum direito ou interesse próprio que possam ser prejudicados pela sentença". ${ }^{22}$

\section{EFICÁCIA DA SENTENÇA}

Classificam-se as sentenças por variados critérios. Por exemplo, conforme solucionem a lide ou não, são definitivas ou terminativas. Entretanto, a classificação a que a doutrina empresta maior relevância, tendo em mira o conteúdo do provimento jurisdicional, distingue três espécies de sentenças: declaratórias, condenatórias e constitutivas. O conteúdo declaratório visa declarar a existência ou inexistência de relação jurídica ou autenticidade ou falsidade de documento; o conteúdo condenatório impõe ao réu uma prestação e o conteúdo constitutivo cria, modifica ou extingue relação jurídica.

Tal nomenclatura, sem embargo de adotada pelo maior número dos processualistas em nosso país, revela-se insuficiente, como

\begin{tabular}{lllll}
\hline R. Fac. Direito Curitiba & a. 25 & n. 25 & p. $93-108,1989$ & 97
\end{tabular}


pondera BOTELHO DE MESQUITA, que a acompanha "não tanto pelo fato de traduzir efetivamente o conteúdo de cada uma destas espécies de sentença, como pelo fato de que a simples mudanga de denominações, além de ter contra si a força de uma poderosa tradição na ciência processual, não implicaria alteração quanto ao objeto do nosso estudo". ${ }^{23}$ COUTURE, de sua vez, assinala que a concepção tradicional é "aproximadamente exata", acrescentando-lhe as sentenças preventivas. ${ }^{24}$ PONTES DE MIRANDA entende superada a doutrina dominante, que divide as sentenças de declaratórias, condenatórias e constitutivas, ensinando que se deve classificar as ações "por aquilo que se espera da sentença, se a ação for julgada procedente"; sustenta a partição qüinária das sentenças, em declaratórias, condenatórias, constitutivas, mandamentais e executivas; leciona haver em todas todos os cinco elementos e que a classificação obedece ao elemento preponderante ${ }^{25}$, aspecto que não escapou a COUTURE. 26

O ensinamento de FONTES DE MIRANDA, a nosso ver, é o que melhor atende ao variado conteúdo das sentenças, e por conseqüência, à sua eficácia. Por outro aspecto, os conteúdos executivo e mandamental não podem ser vistos de modo nenhum como condenatórios, tal como posto pela doutrina tradicional. São irredutíveis. OVIDIO BAPTISTA DA SILVA, que adota a classificação proposta por PONTES DE MIRANDA, explica-se com proficiência. ${ }^{27} \mathrm{O}$ conteúdo executivo é aquele que contém, imanente em si mesmo, como eficácia interna que lhe é própria, o poder de operar uma mudança no mundo exterior (...), compreendida tal mudança como correspondendo a uma transferência de valor jurídico do patrimônio do demandado para o patrimônio do demandante, onde tal valor deveria estar. ${ }^{28}$ Alerta PONTES DE MIRANDA para o gravíssimo erro que seria só termos como ações executivas as ações executivas de sentenças e as ações executiva de títuIos extrajudiciais. Há muitas outras. Pensemos, como exemplos; na ação de reintegração de posse, na de reinvidicação, na de petiçã́o de herança, na do pré-contraente comprador para exigir o cumprimento, com adjudicação, na do pré-contraente vendedor para a execução da dívida de declaração de vontade, na de depósito, na de imissão de posse. ${ }^{29}$ Por outra parte, o conteúdo mandamental exige que alguma pessoa atenda, imediatamente, ao que o juízo manda. ${ }^{30}$ Exemplos de sentenças em que o conteúdo mandamental predomina, temos no mandado de segurança, na ação de manutenção de posse, nas ações (cautelares) de arresto, seqüestro, depósito de filhos, busca e apreensão etc.

Vistos por essa forma os cinco elementos que a sentença com- 
porta, cumpre referir à eficácia como integrante do "ser" da sentença, consistindo na sua aptidão para produzir efeitos. Consoante nomenclatura usada por PONTES DE MIRANDA, que adotamos, a eficácia sentencial compreende a força (quando preponderante) e os efeitos, duas classes de eficácia. Disso concluimos que a eficácia da sentença, ou "eficácias" como bem sugere OVÍDIO, irradiam os efeitos declaratório, condenatório, constitutivo, mandamental e executivo.

\section{EFICÁCIA DA SENTENC̨A E COISA JULGADA}

Estatui 0 art. 472 do C.P.C., primeira parte: "A sentença faz coisa julgada às partes entre as quais é dada, não beneficiaindo, nem prejudicando terceiros". Tal disposição remonta ao conceito dos romanos: "res inter alios indicatae nullum aliis praeiudicium faciunt" (Digesto, 44,2,7), princípio mantido nas Ordenações do Reino, Afonsinas (Livro III, Tit. LXXXV), Manuelinas (Livro III, Tit. LXVII) e Filipinas, nestes termos: "Posto que a sentença não aproveita, nem empece mais que às pessoas entre as quais é dada, poderá porém dela ap̣elar não somente cada um dos litigantes, que se dela sentir agravado, mas ainda qualquer outro, a que o feito possa tocar, e lhe da sentença possa vir algum prejuizo". (Livro III, Tit. LXXXI).

A definição da relação jurídica processual, de que resulta a coisa julgada, torna-se obrigatória para as partes, mas segundo a sempre lembrada lição de CHIOVENDA "como todo ato relativamente às partes entre as quais intervém, a sentença existe e vale com respeito a todos; assim como o contrato entre $A$ e $B$ vale com respeito a todos, como contrato entre $A$ e $B$, assim também a sentença entre $A$ e $B$ vale com relação a todos, enquanto é sentença entre $A$ e $B$ ". ${ }^{31}$ Dessa forma, a decisão judicial, proferida em demanda entre A e B e a eles dirigida, impõe-se perante todos como ato jurídico de relevo, mas não pode prejudicar estranhos ao processo.

Além do que ficou dito nos ítens anteriores, cumpre pôr em claro a distinção entre eficácia da sentença e coisa julgada.

Da eficácia irradiam-se efeitos. A sentença tem eficácia ou eficácias, declaratória, condenatória, constitutiva, mandamental e executiva.

A coisa julgada, entretanto, seja vista como eficácia da sentença ou soma dos efeitos dela, ou ainda, qualidade especial dos seus efeitos, não terá, necessariamente, a mesma área de incidência, que a eficácia sentencial. Escreve a respeito LIEBMAN: "Pode,

\begin{tabular}{llllll}
\hline R. Fac. Direito Curitiba & a. 25 & n. 25 & p.93-108, 1989 & 99
\end{tabular}


portanto, muito bem acontecer que os efeitos da sentença se produzam fora do âmbito em que opera a coisa julgada, a qual torna os próprios efeitos imutáveis". ${ }^{32}$

O estatuto processual civil, em seu art. 467 conceitua a coisa julgada material como "eficácia da sentença" que lhe dá imutabilidade e indiscutibilidade, apartando-se da teoria de LIEBMAN, como observa ARRUDA ALVIM "onde se confunde coisa julgada material, com eficácia". ${ }^{33}$ Censura também a redação desse dispositivo legal ADA GRINOVER, nas anotações à obra de LIEBMAN, "devendo lamentar-se a redação defeituosa do art. 467, C.P.C., que, a pretexto de definir a coisa julgada material, acaba dando o conceito de coisa julgada formal". ${ }^{34}$ Por conseqüência, não se afigura a letra da lei, caminho seguro para o cotejo entre eficácia sentencial e coisa julgada.

Pela teoria de LIEBMAN, exposta em sua multicitada e clás. sica obra, a coisa julgada não é efeito da sentença, mas uma qualidade, um modo de ser e de manifestar-se dos seus efeitos, quaisquer que seja, vários e diversos, consoante as diferentes categorias de sentenças. Na doutrina ciássica, a coisa julgada reside na função declaratória da sentença, tão somente, conforme entendimento de jurista de vulto, como GOLDSCHMIDT, HELLWIG, CHIOVENDA, CARNELUTTI, REDENTI, BETTI, entre nós PONTES DE MIRANDA, CELSO NEVES, importando referir a assertiva de REDENTI de que os provimentos jurisdicionais operam como todos os outros atos do Estado, tendentes a operar sobre relações jurídicas, como opera, por exemplo, um decreto de expropriação. ${ }^{35}$

OVÍDIO BAPTISTA DA SILVA entende a coisa julgada como a qualidade que se adiciona, em dadas circunstâncias, ao efeito declaratório da sentença, tornando-o indiscutível. ${ }^{36}$

Quanto à relação entre a eficácia sentencial e terceiros, LIEBMAN distingue a eficácia natural da sentença da autoridade da coisa julgada, de molde a atingir a esfera dos terceiros, aquela, e restrita exclusivamente às partes no processo, esta.

A doutrina de OVIDIO restringe a coisa julgada, como declaração indiscutível, às partes na relação processual, mas os efeitos da sentença, estes se operam erga omnes.

A teoria clássica considera os efeitos sentenciais que influiriam na esfera jurídica de terceiros, chamando-os de "efeitos e reflexos" ou "efeitos de fato".

O nosso Código de Processo Civil revela, em algumas passagens, admitir a possibilidade de que os efeitos da sentença possam atingir a área de interesse de terceiros, como se vê da assistência (art. 50), reservada ao "terceiro que tiver interesse jurídico", ou 
da chamada assistência litisconsorcial (art. 54). Igualmente quanto ao recurso do terceiro prejudicado (art. 499 e $\S 1$ 10). Isso não obstante, o art. 472 veda à coisa julgada atingir a esfera jurídica dos estranhos. Daí resulta que o Código distingue da coisa julgada os efeitos da sentença.

Estas considerações podem demonstrar que se trata freqüentemente de maneira inadequada a problemática da coisa julgada em relação a terceiros, visto como é assente nas posições doutrinárias referidas, como também no estatuto processual civil, que a coisa julgada não desborda do processo em que foi produzida, vale dizer, não vai além das partes na respectiva relação jurídica processual. Mas a sentença, esta pode atingir e freqüentemente atinge estranhos ao processo, não por força da coisa julgada, repitase, mas sim por obra da eficácia da decisão.

Nessa ordem de considerações, cumpre admitir-se que a sentença tem eficácia assim para os partícipes da relação processual, como para os terceiros, importando distinguir, que se reveste do selo da imutabilidade em relação às partes, e não perante os terceiros, os quais, tendo interesse jurídico poderão impugnar os efeitos danosos. ${ }^{37}$

\section{EFICÁCIA DA SENTENCCA E \\ COISA JULGADA PERANTE TERCEIROS}

Chegados a este ponto, podemos examinar os casos em que o conteúdo da sentença, vale dizer, sua eficácia, projeta-se ultra partes.

Para alcançarmos essa finalidade cumpre distinguir as categorias dos terceiros, observando se e como a sentença pode atingi-los.

MONIZ DE ARAGÃO, em recente estudo, serve-se de resenha feita por LIEBMAN a respeito de cuidadosa exposição de BETTI, expondo também a opinião de CHIOVENDA, de molde a agrupar os estranhos ao processo em razão do seu possível interesse. ${ }^{3 \hat{\gamma}}$

Passemos agora a expor essa concepção, que inicialmente subordina a extensão subjetiva da coisa julgada a dois princípios básicos: um, negativo, fundamenta-se na irrelevância da coisa julgada para os estranhos ao processo em que surgiu; outro, positivo, por força do qual a decisão proferida entre as partes opera também em relação a determinados terceiros, como coisa julgada que se formou entre essas partes.

O primeiro princípio revela-se sob dois aspectos: um relativo aos sujeitos de relação praticamente compatível com a decisão

\begin{tabular}{llll}
\hline R. Fac. Direito Curitiba & a. 25 & n. 25 & p. $93-108,1989$
\end{tabular} 
pron'unciada entre as partes e que podem sofrer, em conseqüência, prejuízo de fato, mas não prejuízo jurídico (terceiros juridicamente indiferentes); outro, pertinente aos sujeitos de relação jurídica incompatível com a decisão pronunciada entre as partes e que não devem, por força da sentença, sofrer prejuízo algum (terceiros juridicamente interessados).

O segundo princípio também assume duas formas diversas: a primeira concerne aos terceiros partícipes da relação deduzida em juízo, por conseqüência de posição "subordinada à posição de uma das partes em causa"; a outra refere-se aos terceiros estranhos à relação decidida, a qual não pode ser desconhecida por eles, cuja relação, embora diversa, é compatível com a decidida, objeto da coisa julgada.

Da combinação desses dois princípios, positivo e negativo, ressurte a classificação dos terceiros em três grupos: a) terceiros juridicamente indiferentes; b) terceiros juridicamente interessados, titulares de relação jurídica incompatível com a sentença e, por isso, imunes à coisa julgada, e c) terceiros juridicamente interessados, sujeitos, entretanto, à coisa julgada por vínculo de subordinação "à narte com referência à relação decidida", tendo de reconhecer o julgado.

Será de utilidade ressalvar destituídos de qualquer interesse doutrinário os terceiros não alcançados de qualquer forma pela sentença, ou seja, completamente desinteressados dela.

Examinemos mais detidamente cada uma dessas categorias.

A) Terceiros juridicamente indiferentes. Estes reconhecem a sentença como ato estatal, mas não têm atingidas as relações jurídicas de que sejam titulares. A eficácia sentencial não lhes afeta a órbita dos interesses jurídicos. No entanto, como sujeitos de alguma relação jurídica compatível com a sentença podem sofrer prejuízo de fato, tal o caso do credor que vê o devedor receber condenação judicial que o leva à insolvência. Ou, em outro exemplo, se $\mathrm{A}$ é credor de B e C credor de A, e ocorre sentença de prescrição quanto a essa cobrança entre A e B, C, que pretendia penhorar esse crédito, não poderá fazê-lo, sentindo-se em prejuízo. Outra hipótese: A move ação de reividicação contra B obtendo sucesso. C, credor de B sofre prejuízo por perder a garantia do seu crédito, o bem reivindicado.

Em todos esses casos, inocorre prejuízo jurídico porquanto os prejudicados não são titulares de relações jurídicas atingidas pelas decisões. Não há incompatibilidade entre o direito reconhecido em juízo e o direito ou interesse jurídico do estrariho ao processo. 0

Curitiba

a. 25

n. 25

p. $93-108,1989$ 
prejuízo aconteceu somente no plano fático. ${ }^{39} \mathrm{E}$ sendo assim, o terceiro terá de resignar-se com a decisão.

Na realidade, nesses casos dos terceiros juridicamente indiferentes, a sentença pode alcançá-los menos como ato de prestação jurisdicional e mais como fato. Veja-se o didático exemplo formulado por OVÍDIO, pelo qual o terceiro nada terá a ver com a sentença que conceder divórcio a certo casal, mas será atingido por ela, de fato, por permitir-lhe contrair matrimônio com o cônjuge divorciado. Abstraindo-nos do plano das relações jurídicas controvertidas, vale mencionar hipótese consistente no empecilho (podendo configurar prejuízo) ao terceiro que a vizinha edificação, autorizada por órgão público, lne causa, ao privá-lo do sol da manhã. Uma conseqüência de fato, sem afronta a direitos.

B) Terceiros juridicamente interessados. São titulares de relação jurídica autônoma, portanto imunes à res iudicata, mas sujeitos à eficácia reflexa da sentença. Nesse caso, a eficácia sentencial direta reflete-se na relação jurídica conexa. Esses terceiros, digados à relação jurídica litigiosa por conexão, "seriam prejudicados juridicamente se tivessem de reconhecer o julgado" diz CHIOVENDA. ${ }^{40}$ Como exemplo, temos a sentença que julga procedente ação reivindicatória entre A e B. C, também com título de propriedade sobre o mesmo imóvel e sem ter ciência do procescesso, permanece imune à coisa julgada. Verifiquemos exemplo de eficácia reflexa na decisão que decreta rescisão de contrato de locação e o despejo do locatário, face ao sublocatário. À força do disposto pelo art. 1.203 do Código Civil, "rescindida, ou finda, a locação, resolvem-se as sublocações", executando-se o despejo mesmo contra o sublocatário. De forma semelhante se dá com a fiança, em que a decisão proferida sobre a relação principal influi certamente na relação subordinada mantida pelo terceiro, porquanto esta não pode manter-se, ou mesmo existir sem aquela. Julgada procedente ação proposta contra o devedor da obrigação principal, poderá o fiador beneficiar-se, a teor do art. 1.502 do Código Civil.

Essa classe de terceiros, como vimos anteriormente, não é atingida pela coisa julgada (para nós, qualidade da eficácia décla ratória da sentença) mas recebe os efeitos reflexos do decisum.

Embora sejam os interesses dos terceiros atingidos pela eficácia reflexa do julgado, isso não significa que eles devam permanecer inertes. A eficácia sentencial atinge-lhes os interesses si et quantum, podendo afastá-la se demonstrarem a injustiça da decisão. Não é outra a opinião de LIEBMAN: "Superam-se, ao contrário, as angulosidades dessa rígida alternativa e se resolve o problema de modo unitário, conforme tanto aos princípios quanto à

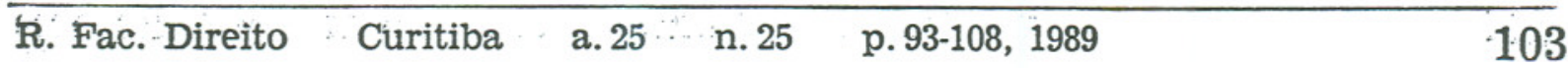


eqüidade, se se sustentar que tum a sentença eficácia também. para o terceiro, admitindo-se, porém, que este último, não estando sujeito à autoridade da coisa julgada, possa, em cada vez e quando tiver interesse, demonstrar a injustiça da sentença e repelir, de conseguinte, o efeito danoso que ela lhe acarretaria". ${ }^{41}$

Em defesa dos seus direitos, os estranhos ao processo podem intervir no feito na qualidade de assistentes simplos (art. 50, C.P.C.), submetendo-se às regras aplicáveis (art. 55). Também podem fazer uso da oposição (art. 56) se for o caso, ou do recurso reservado ao terceiro prejuảicado (art. 499 e $\S 1$ ()). Da mesma forma, as hipóteses previstas no art. 1.046, C.P.C. fazem dos embargos de terceiro meio idôneo de defesa. A ação rescisória reveste-se de legitimidade $e x-v i$ do art. 487, II, observada a casuística do art. 485.

Não se pode eliminar a faculdade de o terceiro ajuizar ação autว̂noma quando titular de relação jurídica incompatível e suscetível de prevalecer sobre o decidido. ${ }^{42}{ }^{4} 3$

C) Terceiros juridicamente interessados, titulares de relação subordinada à relação decidida.

Essa categoria de terceiros envolve a sucessão e a substituição processuais.

Não obstante LIEBMAN, CHIOVENDA, BETTI, os considerarem terceiros, boa parte da doutrina ${ }^{44}$ discorda. Com efeito, pensamos que a identidade das partes exigida à identidade da ação (cf. art. $301 \S 2$ o do C.P.C.) deve ser vista sob a ótica da sua qualidade jurídica, como estabelecem aliás, o Código de Processo Civil português em seu art. $4989,2^{45}$ e o Código Civil italiano, no seu art. $2.909^{46}$ qual já previa o Digesto (Livro 44,2,14) ..."eadem conditio personarum".

Nessa linha de raciocínio, há considerar não só a sucessão mortis causa como também entre vivos (compra, doação, permuta, transação, expropriação etc.). Na sucessão entre vivos, permanecendo os mesmos objeto e causa de pedir, a alteração de sujeito na re'ação processual em função de posição junto ao direito material controvertido, submete à coisa julgada sucessor e sucedido, substituto e substituído, até pelo disposto no art. 42 do C.P.C.

De outra parte, indiferente se nos antolha, tendo em vista a incidência da coisa julgada, a alteração da parte antes, durante ou após o julgamento do processo (cf. art. $42 \S 3$ 9, C.P.C.) $.^{47}-48$

\section{AÇÕES DE ESTADO E EFICACIA "ERGA OMNES"}

Estabelece o art. 472, segunda parte, do Código de Processo

R. Fac. Direito Curitiba

a. 25

n. 25

p. $93-108,1989$ 
Civil: "Nas causas relativas ao estado de pessoa, se houverem sido citados n p processo, em litisconsórcio necessário, todos os interessados, a sentença produz coisa julgada em relação a terceiros".

Informa MONIZ DE ARAGÃO em seu estudo já referido, que o legislador inspirou-se nesse passo no Código de Processo Civil português, art. $6740^{49}$

CASTRO MENDES, ${ }^{50}$ MANUEL DE ANDRADE,51 ANTUNES VARELA, MIGUEL BEZERRA E SAMPAIO E NORA ${ }^{52}$, autores portugueses, censuram o dispositivo do código luso. O nosso não colhe melhor sorte. LIEBMAN manifestou-se contrariamente a esse preceito, dizendo: "Não se pode admitir que uma pessoa, a respeito da qual se produz o efe to constitutivo da sentença, nã̃o deva reconhecer também como eficaz a declaração de direito que na mesma sentença justifica e legitima a mudarişa que o juiz introduz na relação jurídica controvertida". ${ }^{53}$

De fato, nas chamadas ações de estado, a relação controvertida versa sobre o estado da pessoa, seja status familiae (estado familiar) ou status civitatis (estado de cidadania) ou, genericamente, como escreve MONIZ DE ARAGÃO: "nele se intensifica, em suas várias formas, a capacidade jurídica subjetiva, como conjunto de poderes e deveres dos quais o sujeito é investido pelo ordenamento jurídico"..54

Nas causas de estado o que ocorre, na realidade, nos diversos casos que pudemos imag nar, é que a sentença revela eficácia preponderantemente constitutiva, ou seja, cria, modifica ou extingue determinada relação jurídica. Ensina a respeito PONTES DE MIRANDA: "Não há eficácia erga omnes de coisa julgada material nas ações de estado. O que é erga omnes, nelas, é a eficácia da constitutividade. A confusão entre as duas eficácias tem levado a erros sem conta". ${ }^{55}$

A coisa julgada, tal como nos demais casos, opera tão somente inter partes. Assim, por exemplo, nas ações de investigação de paternidade ou de maternidade, de nulidade ou de anulação de casamento, de interdição, de emancipação, de suspensão do pátrio poder etc. Em todas essas demandas a sentença terá eficácia predominantemente constitutiva, em sua tipicidade de criar, modificar ou extinguir relação jurídica. Vejamos o seguinte exemplo: A pede e obtem interdição de B. A sentença que decretou a interdição de B tem a eficácia de tornar nulos os contratos firmados por B com C, D, e E, ao menos a partir da publicação da sentença (cf. art. 1.184, C.P.C.). Trata-se de eficácia constitutiva negativa da decisão.

Quanto à ciência do processo a todos os interessados, é ques-

\begin{tabular}{lllll}
\hline R. Fac. Direito Curitiba & a. 25 & n. 25 & p.93-108, 1989 & 105
\end{tabular}


tão de legitimação que se resolve pelo conhecido princípio que determina a citação de todos os interessados na causa. $\mathrm{E}$ o conceito de litisconsórcio necessário, a que se referem as verba legis, não se apresenta diverso para as questões de estado. Exemplifiquemos com exemplo de MANUEL DE ANDRADE ${ }^{56}$ : A e B tiveram seu casamento julgado existente e válido, em processo em que somente os dois foram partes. Isso não basta a que $\mathbf{C}$, estranho a esse pleito, sustente em novo processo ser ele o verdadeiro cônjuge de A.

A legitimação rege-se pelos princípios gerais, sem necessidade da menção específica do art. 472, segunda parte, do C.P.C. Não há distinguir os interessados referidos por esse preceito do "legítimo interesse" exigido pelo art. $3^{0}$ do C.P.C.

Acompanhamos, portanto, a conclusão a que chegou MONIZ DE ARAGÃO, ao afirmar sobre a referida previsão do art. 472: "A segunda parte da disposição em exame exprime o mesmo princípio inscrito na primeira, a qual soluciona por si só todas as hipóteses, incluidas as causas sobre o estado das pessoas". ${ }^{57}$

\section{NOT A S}

(1) ELIÉZER ROSA, "Dicionário de Processo Civil", 2." ed., São Paulo, José Bushatsky, 1973, p. 317.

(2) "Tanto que a lide se apresenta como endividada nos três únicos elementos diferenciais que Carnelutti enumera, ela pertence ao mundo sociológico, não ao mundo jurídico" (CALAMANDREI, II Concetto di "Lite" nel Pensiero di Francesco Carnelutti ( . $^{\circ} 11$ ) Rivista di Diritto Processuale Civile (1928) V-1/93). No mesmo sentido LIEBMAN (O Despacho Saneador e o Julgamento do Mérito n. 7). Estudos Sobre o Processo Civil Brasileiro, 2. ${ }^{a}$ ed., p. 117).

(3) "Instituições de Direito Processual Civil", 3. ed., São Paulo, Saraiva, 1969, vol. I, p. 118 e 369), trad. brasileira.

(4) GABRIEL REZENDE FILHO, "Curso de Direito Processual Civil", 7.a ed., São Paulo, Saraiva, 1966, vol. III, p. 54.

(5) "Accomodadas ao Fôro do Brasil até o anno de 1877" por AUGUSTO TEIXEIRA DE FREITAS, Rio, editora H. Garnier, 1.907, p. 219.

(6) “Tratado das Ações”, São Paulo, RT, 1970, tomo I, p. 182.

(7) “Coisa Julgada Civil”, São Paulo, ed. RT, 1971, p. 504.

(8) "Eficácia e Autoridade da Sentença", 3.a ed., São Paulo, Forense, 1984.

(9) “Temas de Direito Processual”, primeira série, 2.a ed., São Paulo, 1988, p. 89.

(10) MONIZ DE ARAGÃO entende como situação jurídica " $a$ de um sujeito considerado em relação a um ordenamento jurídico (diversamente do que se dá com a relação jurídica " $n a$ qual um sujeito confronta-se com outro, ou outros, sujeitos")", in "Observações Sobre os Limites Subjetivos da Coisa Julgada", "Revista dos Tribunais", vol. 625, p. 17.

(11) "Curso de Processo Civil", vol. I, Porto Alegre, Sergio Fabris, 1987, p. 428.

(12) PONTES DE MIRANDA, "Comentários ao Código de Processo Civil" (1973), Rio, Forense, 1974, p. 203. 
(13) "Instituições de Direito Processual Civil, 3.a ed., vol. II, São Paulo, Saraiva, 1959, p. 234, trad. bras.

(14) Como ocorre, verbi gratia, na ação declaratória de inexistência de relação jurídica julgada procedente.

(15) Exemplifica OVIDIO BAPTISTA DA SILVA com o falso credor, ainda de má fé, que proponha a demanda fazendo-se passar por credor verdadeiro, é sujeito da relação processual e sujeito da lide (in ob. cit., p. 189).

(16) Caso em que a relação substancial descrita reste improvada ou improvada sua titularidade por qualquer das partes.

(17) GIUSEPPE CHIOVENDA, ob. cit., 2..$^{\circ}$ vol., p. 234.

(18) “Tratacio das Ações”, tomo I, São Paulo, ed. RT, 1970, p. 255.

(19) "Instituições de Direito Processual Civil", 3. ${ }^{a}$ ed., vol. V, Rio, Forense, 1971, p. 301.

(20) “Tratado das Ações", tomo VI, São Paulo, RT, 1976, p. 195.

(21) O Código refere-se à ação, mas nos parece de inteira razão a preferência de HUMBERTO THEODORO JR. ("Curso de Direito Processual Civil", vol. I, 2. ed., Rio, Forense, 1966, p. 66) pelo termo causa; J. J. CALMON DE PASSOS ("Comentários ao C.P.C.", vol. III, Rio, Forense, p. 259) utiliza o vocábulo lide; FREDERICO MARQUES ("Manual de Dir. Proc. Civ.", 1. vol., São Paulo, Saraiva, 1974, p. 153) entende que se tratam dos elementos identificadores da ação.

(22) Ob. cit., p. 215.

(23) “Da Ação Civil”, São Paulo, RT, 1975, p. 102/103.

(24) "Introdução ao Estudo do Processo Civil", 3. ${ }^{a}$ ed., José Konfino, p. 85, trad. bras.

(25) “Tratado das Ações", tomo I, São Paulo, RT, 1970, p. 177 e segs. et passim,

(26) Ob. e loc.cit.

(27) "Sentença e Coisa Julgada", Porto Alegre, Fabris, 1979, p. 95 e segs.; "Curso de Processo Civil", Porto Alegre, Fabris, 1987, p. 93 e segs.

(28) OVIDIO A. BAPTISTA DA SILVA, "Sentença e Coisa Julgada", Porto Alegre, Fabris, 1979, p. 101.

(29) “Tratado das Ações", tomo VII, São Paulo, RT, ps. 03/04.

(30) “Tratado das Ações", tomo VI, São Paulo, RT, 1976, p. 03.

(31) “Instituições de Direito Processual Civil”, 1/414, São Paulo, Saraiva, 1969, trad. brasileira.

(32) Ob. cit., p. 123

(33) "Código de Processo Civil Comentado", São Paulo, RT, 1976, p. 121.

(34) Ob. cit., p. 09. No mesmo sentido PONTES DE MIRANDA ("Comentários ao C.P.C." (1973), tomo V, Rio, Forense, 1974, p. 145.

(35) apud ENRICO TULLIO LIEBMAN, ob. cit., p. 20.

(36) “Curso de Processo Civil”, vol. I, Porto Alegre, Fabris, 1987, p. 428.

(37) Nesse sentido: LIEBMAN, ob. cit., p. 190; FREDERICO MARQUES, "Manual de Direito Processual Civil”, São Paulo, Saraiva, 1975, vol. 3, 1975, p. 241; ARRUDA ALVIM, ob. cit., p. 130.

(38) "Observações sobre os limites subjetivos da coisa julgada", in "Revista dos Tribunais", vol. 625, p. 09.

(39) Sabidamente, a eficácia sentencial produz alterações no mundo fático. Temos então, dois planos a considerar: o fático e o jurídico. Será incorrer em obviedade afirmar que nem toda alteração no mundo fático faz incidir regra jurídica. Essa colocação, entretanto, ajuda a compreender que só de fatos jurídicos (ou seja, aqueles que interessam ao mundo jurídico) provêm relações jurí-

\begin{tabular}{llllll}
\hline R. Fac. Direito & : Curitiba & a. 25 & n. 25 & p. 93-108, 1989 & 107
\end{tabular}

(bI) Ub. c1t., p. 315.

(52) Ob. cit., p. 730.

(53) Ob. cit., p. 196.

(54) Estudo e revista citados, p. 17.

(55) “Tratado das Ações", tomo I, São Paulo, RT, 1970, p. 200.

(56) Ob. cit., p. 315.

(57) Estudo e revista citados, p. 21. 